\title{
Determinants of Delay in First Prenatal Consultation at Hospital Environment in Kimpese Health Zone in Democratic Republic of Congo: Cross-sectional Study
}

\author{
Likongo Botawaosenge Ted ${ }^{1}$, Nkodila Natuhoyila Aliocha ${ }^{2,}$, Lukanu Ngwala Philippe ${ }^{1}$, \\ Matondo Batumanitu Joel ${ }^{1}$, Mbungu Mwimba Roger ${ }^{3}$ \\ ${ }^{1}$ Department of Medecine Family, Protestante University of Congo, Kinshasa, Democratic Republique of Congo \\ ${ }^{2}$ Department of Public Health, Lomo University Reseach, Kinshasa, Democratic Republique of Congo \\ ${ }^{3}$ Department of Gynecology Obstetric, University of Kinshasa, Kinshasa, Democratic Republique of Congo
}

Email address:

nkodilaaliocha@gmail.com (N. N. Aliocha)

${ }^{*}$ Corresponding author

\section{To cite this article:}

Likongo Botawaosenge Ted, Nkodila Natuhoyila Aliocha, Lukanu Ngwala Philippe, Matondo Batumanitu Joel, Mbungu Mwimba Roger. Determinants of Delay in First Prenatal Consultation at Hospital Environment in Kimpese Health Zone in Democratic Republic of Congo: Cross-sectional Study. Journal of Health and Environmental Research. Vol. 6, No. 3, 2020, pp. 98-103. doi: 10.11648/j.jher.20200603.18

Received: July 17, 2020; Accepted: July 28, 2020; Published: September 19, 2020

\begin{abstract}
Context and aims: knowledge of determinants of delay in prenatal consultations is essential if we want to reduce maternal and infant mortality. The aims of this study is to determine the factors determining the delay in the first prenatal consultation (PNC 1) in a hospital setting in the Kimpese Health Zone. Methods: We conducted a cross-sectional study, including recruited women, by random sampling in prenatal consultations in the Kimpese Health zone; between June 1 and August 31, 2017. It consisted in directly collecting, through an interview, information on the socio-demographic and economic characteristics and the first prenatal consultation of the women followed in the health areas of this Health Zone. Results: of the 431 women included in the study, $87.5 \%$ had a delay in PNC 1. Their average age of women was $36.4 \pm 6.8$ years. Having a non-spouse head of household multiplied the risk of PNC 1 delay 1 by 2 (ORa: 1.95 95\% CI: 1.01-3.78), having an existing fixed place of PNC 1 increased the risk of delay of PNC by 8 (ORa: 7.69; 95\% CI: 2.56-25.00) and the absence of PNC 1 cost coverage increased the risk of CPN delay 1 by 3 (ORa: 3.33; 95\% CI: 1.15-9.09). Conclusion: The frequency of PNC 1 delay is high in Kimpese Health Zone. It is associated with the non-spouse head of household, the existing PNC location and the absence of PNC cost coverage.
\end{abstract}

Keywords: Delay of PNC 1, Determinants, Kimpese Health Zone

\section{Introduction}

Maternal health is an important indicator of a country's development, as well as a major public health concern. It takes into account all aspects of a woman's health from pregnancy to childbirth until postpartum [1].

The pregnant woman is taken care of during prenatal consultations which constitute a privileged moment to ensure the well-being of a future childbirth and her future child. Beyond the link, already essential in itself, prenatal consultation is also a public health tool as long as it is only the simple act of ensuring quality follow-up, plays a role in prevention and early management of pregnancy complications thereby improving maternal and child health [1].

The World Health Organization (WHO) recommended 4 antenatal consultations: the first in the first trimester of pregnancy, before 14 weeks depending on the date of the last period; the second in the second trimester of pregnancy; the third in the third trimester of pregnancy and the fourth necessarily in the ninth month of pregnancy $[1,2]$. The latter should be oriented towards the prognostic evaluation of childbirth, and will look for potential causes of obstructed labor [3]. And each trimester corresponds to a package of specific interventions in the field of prevention and screening that all pregnant women are expected to benefit. Currently, 
the number doesn't matter; It is more the quality of the services offered that counts [4]. Hence any delay in registering for antenatal care is synonymous with a lack of quality health interventions for the said woman.

The prevalence of delay in antenatal care varies between 2.8 and $16 \%$ in Europe and the United States of America [5]. At a time when the late attendance of pregnant women to antenatal care hardly concerns vulnerable and minority populations in developed countries, this phenomenon remains a real problem in emerging countries such as the Democratic Republic of Congo and constitutes a factor limiting effectiveness. prenatal consultations for the outcome of the pregnancy [5]. This frequency is higher in Africa, estimated at $80 \%[6,7]$ in the DRC at $73 \%$ according to the 2014 DHS [8]. In rural Kongo Central, an audit of data from the 2015 prenatal consultations of the General Reference Hospital of the Evangelical Medical Institute (IME) revealed that $86.2 \%$ of pregnant women had presented for their first aid late prenatal care, ie after the 16th week of amenorrhea [9]. Faced with this situation, we consulted the data compiled from the Central Office of the Health Zone on antenatal consultations. The indicators "first prenatal consultation" (PNC 1) and "fourth prenatal consultation" (PNC 4) were overdue, with a late character for PNC1. We wanted to know what the reasons were; hence the objective of this study to determine the factors determining the delay in the first prenatal consultation in a hospital setting in the Kimpese Health Zone.

\section{Material and Methods}

\subsection{Type, Setting and Study Population}

Through a multicenter cross-sectional study, 431 women from all types of antenatal consultations were interviewed in the health centers of the Kimpese health zone between June 1 and August 31, 2017. The study population consisted of all pregnant women expected at the antenatal consultation in the Health Zone. According to forecasts from the Central Office of the Health Zone, based on demographic data from the Democratic Republic of Congo, the number of pregnant women expected globally at the first prenatal consultation amounted to 7,620 equivalent to $4 \%$ of the total population. of the Health Zone, estimated at 190,497 in 2016 (Central Office of the Kimpese Health Zone, 2016). Given that the average attendance rate was $54 \%$, the strictly expected women numbered 1,029 over a period of 3 months [10].

Using the sample size calculator "Sample Size Calculator for Prevalence Studies" version 1.0.01 of April 2006, the size of our sample was calculated at 217 pregnant women, the confidence threshold being of $95 \%$. The sampling was carried out in a cluster at 2 levels, according to the proportions: we calculated the average attendance rate of pregnant women to antenatal care services transmitted by each health area, then by each health structure organizing the service. prenatal health care throughout 2016. And this enabled us to identify a percentage of women to be interviewed at each health area first, then at each health structure organizing prenatal care for each health area. We proceeded to the selection of participants according to the order of registration (order of arrival) in the register of antenatal consultations, the same day of antenatal care, until reaching a quota for each health facility. The calculated sample size of 217 individuals was doubled to 434 in order to reduce the cluster effect which is a selection bias. After data analysis, 3 incomplete survey forms were excluded from the study, reducing our study sample to 431 pregnant women.

The data was collected using a pre-test questionnaire intended for pregnant women who attended the various health facilities organizing prenatal consultations during our collection period. It was carried out with the voluntary collaboration of the nurses in charge of the said health structures, who were, however, motivated with modest financial encouragement. The latter were previously trained and a small test survey was carried out.

To be eligible, subjects should meet the following inclusion criteria: have consulted at the health center for antenatal care during the study period; agree to participate in the study. Women with no mental faculties who refused to answer our questions were not included in the study. The delay in CPN1: any pregnant woman who initiates the first prenatal visit after the 16 th week of amenorrhea.

\subsection{Statistic Analyzes}

After encoding and validation of the data, they were entered on a computer, using EPI data 3.1 software. Systematic cleaning of the file was carried out by means of the completeness test and the consistency test for the harmonization and validation of data. Data analysis was performed with IBM-SPSS 21 software. Quantitative variables were expressed as mean \pm standard deviation while qualitative variables were expressed as percentages. Student's $\mathrm{t}$ test was used to compare means and Chi-square for proportions. The determining factors of PNC 1 delay were sought by logistic regression using the back ward method (step by step), the degree of association between the PNC 1 delay and the independent variables was estimated by the calculation of 1 'Odd ratio (OR) and their 95\% confidence intervals $(\mathrm{CI})$. The threshold of statistical significance was set at $\mathrm{p}<0.05$.

\subsection{Ethical Considerations}

The study respected the rules of confidentiality, justice and beneficence of women. The protocol for this research study was submitted and approved by the ethics committee of the Protestant University in the Congo under Approval Number CEUPC0037 and the authorization of Chief Medical Officer.

\section{Results}

PNC 1 delay frequency

Of the 431 women interviewed, 377 registered late for antenatal care during our study period, or $87.5 \%$. The socio- 
demographic characteristics of the women are illustrated in Table 1 and show that the average age of women was $36.4 \pm$ 6.8 years, they were mostly in the age group over 20 years (81\%). $73 \%$ resided in the marital home as a couple in $68.7 \%$ with household occupation in $85.6 \%$. Almost half (49.9\%) did not have a diploma. $78 \%$ of spouses had no salary, however graduates in $80 \%$ of the Christian religion. the majority of these women lived in an average family (75.9\%) with $70 \%$ as partner household head.

Compared to women without a delay in PNC 1, those with a delay in CPN1 had a significantly high incidence of unpaid husbands $(69.6 \%$ vs. $8.4 \%$; $\mathrm{p}=0.032)$.

Table 1. Socio-demographic characteristics of women.

\begin{tabular}{|c|c|c|c|c|}
\hline \multirow{2}{*}{ Explanatory variables } & \multirow{2}{*}{ Over all $(n=431)$} & \multicolumn{2}{|c|}{ Explained variable: delay of the 1st PNC } & \multirow{2}{*}{ p-value } \\
\hline & & No $(n=54)$ & Yes $(n=377)$ & \\
\hline Age (years) & $26.37 \pm 6.83$ & $25.94 \pm 6.83$ & $26.43 \pm 6.82$ & 0.788 \\
\hline$<20$ & $82(19.0)$ & $11(2.6)$ & $71(16.5)$ & \\
\hline$\geq 20$ & $349(81.0)$ & $43(10.0)$ & $306(71.0)$ & \\
\hline \multicolumn{5}{|l|}{ Residence } \\
\hline Outside the marital home & $118(27.4)$ & $16(3.7)$ & $102(23.7)$ & 0.692 \\
\hline At the married house & $313(72.6)$ & $38(8.8)$ & $275(63.8)$ & \\
\hline \multicolumn{5}{|l|}{ Marital status } \\
\hline Single & $135(31.3)$ & $16(3.7)$ & $119(27.6)$ & 0.774 \\
\hline Relationship & $296(68.7)$ & $38(8.8)$ & $258(59.9)$ & \\
\hline \multicolumn{5}{|l|}{ Occupation } \\
\hline Student or employee & $62(14.4)$ & $8(1.9)$ & $54(14.4)$ & 0.923 \\
\hline Household & $369(85.6)$ & $46(10.7)$ & $323(74.9)$ & \\
\hline \multicolumn{5}{|l|}{ School diploma } \\
\hline State graduate and more & $216(50.1)$ & $32(7.4)$ & $184(42.7)$ & 0.151 \\
\hline Not graduated & $215(49.9)$ & $22(5.1)$ & $193(44.8)$ & \\
\hline \multicolumn{5}{|l|}{ Joint profession } \\
\hline Employee & $95(22.0)$ & $18(4.2)$ & $77(17.9)$ & 0.032 \\
\hline Unemployed & $336(78.0)$ & $36(8.4)$ & $300(69.6)$ & \\
\hline \multicolumn{5}{|l|}{ Joint level of study } \\
\hline Not a state graduate & $88(20.4)$ & $6(1.4)$ & $82(19.0)$ & 0.073 \\
\hline State graduate and more & $343(79.6)$ & $48(11.1)$ & $295(68.4)$ & \\
\hline \multicolumn{5}{|l|}{ Religion of the respondent } \\
\hline Not christian & $102(23.7)$ & $14(3.2)$ & $88(20.4)$ & 0.676 \\
\hline Christian & $329(76.3)$ & $40(9.3)$ & $289(67.1)$ & \\
\hline Joint religion & & & & 0.517 \\
\hline Not christian & $45(10.4)$ & $7(1.6)$ & $38(8.8)$ & \\
\hline Christian & $386(89.6)$ & $47(10.9)$ & $339(78.7)$ & \\
\hline Household size & & & & 0.742 \\
\hline Large $>6$ peoples & $104(24.1)$ & $14(3.2)$ & $90(20.9)$ & \\
\hline Average $\leq 6$ peoples & $327(75.9)$ & $40(9.3)$ & $287(66.6)$ & \\
\hline Head of household & & & & 0.207 \\
\hline Respondent and other person & $128(29.7)$ & $20(4.6)$ & $108(25.1)$ & \\
\hline Partner & $303(70.3)$ & $34(7.9)$ & $269(62.4)$ & \\
\hline
\end{tabular}

Table 2 summarizes the environmental and socioeconomic characteristics of women according to the delay of the $1 \mathrm{st}$ ANC. It shows that $31.3 \%$ of CPN health center was far from home, $82.1 \%$ used the foot as a means of transport. $69 \%$ waited more than 30 minutes to reach the SC. At the Health Center, more than half of the women $(55 \%)$ waited more than 30 minutes, the cost of ANC costs was provided in the majority of cases by the family (94\%); but in the majority of cases the cost of ANC was affordable (94\%), in the majority of cases the spouse paid for the prenatal care and that the majority of women had a fixed place of ANC.

Compared to women with no CPN1 delay, those with CPN1 delay significantly had a high frequency of waiting times at the SC $(p=0.035)$, family CPN cost coverage $(p<0.001)$, taking charge of prenatal care by the spouses $(\mathrm{p}=0.005)$ and a fixed place of existing ANC $(\mathrm{p}<0.001)$.

Table 2. Environmental and socio-economic characteristics.

\begin{tabular}{llll}
\hline \multirow{2}{*}{ Explanatory variables } & Over all $(\mathbf{n}=\mathbf{4 3 1}) \mathbf{( 1 0 0 )}$ & \multicolumn{2}{l}{ Explained variable: delay of the 1st PNC } \\
\cline { 3 - 4 } & $\mathbf{N o}(\mathbf{n}=\mathbf{5 4})$ & Yes $(\mathbf{n}=\mathbf{3 7 7})$ \\
\hline Is the health center far from home & $135(31.3)$ & $14(3.2)$ & $121(28.1)$ \\
Yes & $296(68.7)$ & $40(9.3)$ & $256(59.4)$ \\
No & & & \\
Means of transport used & $77(17.9)$ & $9(2.1)$ & $68(15.8)$ \\
Gear & $354(82.1)$ & $45(10.4)$ & $309(71.7)$ \\
Walk & $133(30.9)$ & $11(2.6)$ & $122(28.3)$ \\
Time taken to get to health Center & $298(69.1)$ & $43(10.0)$ & $255(59.2)$ \\
$<30$ minutes & & & 0.361 \\
$\geq 30$ minutes & & & 0.806 \\
\hline
\end{tabular}




\begin{tabular}{|c|c|c|c|c|}
\hline \multirow{2}{*}{ Explanatory variables } & \multirow{2}{*}{ Over all $(n=431)(100)$} & \multicolumn{2}{|c|}{ Explained variable: delay of the 1st PNC } & \multirow{2}{*}{ p-value } \\
\hline & & No $(n=54)$ & Yes $(n=377)$ & \\
\hline \multicolumn{5}{|l|}{ Waiting time to health Center } \\
\hline$<30$ minutes & $194(45.0)$ & $17(3.9)$ & $177(41.1)$ & \multirow{2}{*}{0.035} \\
\hline$\geq 30$ minutes & $237(55.0)$ & $37(8.6)$ & $200(46.4)$ & \\
\hline \multicolumn{5}{|l|}{ PNC expense coverage } \\
\hline No & $26(6.0)$ & $13(3.0)$ & $13(3.0)$ & \multirow[t]{2}{*}{0.000} \\
\hline Yes & $405(94.0)$ & $41(9.5)$ & $364(84.5)$ & \\
\hline \multicolumn{5}{|l|}{ Cost of antenatal care } \\
\hline Expensive & $34(7.9)$ & $5(1.2)$ & $29(6.7)$ & \multirow[t]{2}{*}{0.690} \\
\hline Affordable & $397(92.1)$ & $49(11.4)$ & $348(80.7)$ & \\
\hline \multicolumn{5}{|l|}{ Person in charge of prenatal care } \\
\hline Respondent and others & $83(19.3)$ & $18(4.2)$ & $65(15.1)$ & \multirow[t]{2}{*}{0.005} \\
\hline Spouse & $348(80.7)$ & $36(8.4)$ & $312(72.4)$ & \\
\hline \multicolumn{5}{|l|}{ Existence of a mutual health insurance } \\
\hline Yes & $177(41.1)$ & $18(4.2)$ & $159(36.9)$ & \multirow[t]{2}{*}{0.217} \\
\hline No & $254(58.9)$ & $36(8.4)$ & $218(50.6)$ & \\
\hline Fixed and arranged place for the PNC & & & & $<0.001$ \\
\hline Non-existent & $23(5.3 \%)$ & $13(3.0 \%)$ & $10(2.3 \%)$ & \\
\hline Existing & $408(94.7 \%)$ & $41(9.5 \%)$ & $367(85.2 \%)$ & \\
\hline
\end{tabular}

Table 3 illustrates the determinants of delay in PNC 1 in the study population. In univariate analysis, the waiting time of more than 30 minutes at the health center, the absence of salary of the spouse, the non-spouse head of household, the existing place of ANC and the absence of coverage of ANC costs had emerged as determinants of PNC delay 1.

After adjustment in multivariate analysis, the non-spouse head of household, the existing PNC place of residence and the absence of PNC cost coverage were the independent determinants of delay in PNC 1. Having a non-household head joint multiplied the risk of delayed PNC 1 by 2 (aOR: 1.95 95\% CI: (1.01-3.78), $\mathrm{p}=0.047)$, having an existing fixed site of PNC increased the risk of delayed PNC by 8 (aOR: 7.69; 95\% CI: $(2.56-25.00), \mathrm{p}<0.001)$ and the lack of coverage of PNC costs increased the risk of delayed PNC 1 by 3 (aOR: 3.33; 95\% CI: (1.15-9.09), $\mathrm{p}=0.026$ ).

Table 3. Delay determinants of PNC 1.

\begin{tabular}{|c|c|c|c|c|}
\hline Explanatory variables & p-value & Unadjusted OR & p-value & $\overline{\text { Ajusted OR }}$ \\
\hline \multicolumn{5}{|c|}{ Waiting time to health Center } \\
\hline$\leq 30$ minutes & & 1 & & 1 \\
\hline$>30$ minutes & 0,035 & $1.93(1.05-3.54)$ & 0.125 & $1.26(0.15-2.78)$ \\
\hline \multicolumn{5}{|l|}{ Occupation of spouse } \\
\hline Employee & & 1 & & 1 \\
\hline Unemployed & 0,032 & $1.95(1.05-3.62)$ & 0,133 & $1.353(0.14-2.92)$ \\
\hline \multicolumn{5}{|l|}{ Head of household } \\
\hline Not spouse & 0.005 & $2.38(1.28-4.55)$ & 0,047 & $1.95(1.01-3.78)$ \\
\hline \multicolumn{5}{|c|}{ Fixed and arranged place for the PNC } \\
\hline Not-existent & & 1 & & 1 \\
\hline Existing & $<0,001$ & $11,64(4.80-28.20)$ & $<0.001$ & $7.69(2.56-25.00)$ \\
\hline \multicolumn{5}{|l|}{ PNC expense coverage } \\
\hline Yes & & 1 & & 1 \\
\hline No & $<0.001$ & $8.89(3.86-20.44)$ & 0,026 & $3.33(1.15-9.09)$ \\
\hline
\end{tabular}

\section{Discussion}

The early attendance of pregnant women in antenatal care services is the cornerstone in the prevention, detection and management of complications related to pregnancy. Despite the measures and provisions implemented by the various health policies under the patronage of the WHO, late attendance of the first prenatal consultation remains a problem in developing countries, particularly in the Democratic Republic of Congo and precisely in Kimpese Health Zone.

The prevalence of delayed PNC 1 in the Kimpese Health Zone during our study period was very high $(87.5 \%)$. The results of our study join the many studies carried out in sub-
Saharan Africa and South-East Asia, through this high prevalence of delayed PNC 1. Indeed, Chewe et al., [11] reported, in their study on the Ndola health zone in Zambia, that the prevalence of delayed PNC 1 was $86.6 \%$. While for Njiku et al., [12] in Lushoto in Tanzania, this prevalence was $70.4 \%$. Gebremeskel et al., [13] in southern Ethiopia, reported that only $17.4 \%$ of respondents had started their first antenatal visit as recommended before 16 weeks of gestation. Okeudo et al., [14] in their study, reported the prevalence of delayed PNC 1 of $83.5 \%$ and Prakash et al., [15] in Gujarat, India, found that $80.4 \%$ of pregnant women showed up for their first consultation after the scheduled time.

According to EDS RDC 2013-2014, 73\% of pregnant Congolese women had started antenatal care late. Feinstein et al., [16] in their study of 4 health zones in Kinshasa (Binza Météo, 
Bandalungwa, Kisenso and Masina 2) reported that $78 \%$ of women had consulted for their first prenatal consultation after the first trimester. Nsibu et al. [17], in their study of 25 areas of health in the Democratic Republic of Congo, reported that $82.4 \%$ of pregnant women attended antenatal care services for the first time after the first trimester. These various studies show how the problem of delay in enrollment in antenatal care remains major in developing countries, in particular in the Democratic Republic of Congo. Regarding our study environment, this high rate of delay in initiating antenatal care for pregnant women is explained by the multiple medical appointments imposed on the pregnant woman. The woman said to herself, "The later I start medical monitoring of my pregnancy, the less I will have medical appointments. Consequently, there would be less expenses incurred".

PNC 1 delay determinants

After removing the confounding variables, the fact that the non-spouse is the head of the household increased twice the risk of delay in the first prenatal consultation. The existence of a fixed and fixed place where PNC 1 take place had 8 times the risk of late PNC 1. Failure to cover the costs of antenatal care was 3 times the risk of having late PNC 1. Multivariate logistic regression has therefore enabled the emergence of the variable "head of household as a determinant of the delay in the first prenatal consultation in the Kimpese health zone. The fact that the non-spouse was the head of the household increased the risk of having late PNC1 by 2 times. The literature states that when the spouse is involved in her partner's prenatal care, the environment is the woman's access to this service. Houri Boukarl. [18] Found that the participation of the spouse in prenatal care favored a good initiation of prenatal care $(\mathrm{OR}=2.84 ; 95 \% \mathrm{CI}$ : 2.34-23.48). In our study, the fact that the head of the household was the spouse reduced by 2 the risk of having a late PNC 1, this probably because this partner was employed. So in univariate analysis, the self-employed had emerged as a determinant and that the financial constraints for a nonsalaried household head would be the cause of the poor initiation of antenatal care in the Kimpese Health Zone. Hence the need for prenatal care coverage. In households where this care coverage was provided, the risk of delay in PNC 1 was reduced by 3 . This association between delay in PNC 1 and care coverage is linked in the majority of cases to the poor population in the DRC. This situation of poverty does not contribute to a positive rating for carrying out PNC 1. It is also often due to the undesirable nature of the pregnancy of the population, sometimes obtained clandestinely and exposing the victim to the poor family. The positive impact of antenatal care coverage for PNC 1 observed could be explained by the relationship between providers of this care, which conditions knowledge, and perhaps also attitudes and practices in the face of health phenomena $[19,20]$.

This study could have certain limitations. As the study is cross-sectional, the cause and effect relationship between the delay in PNC 1 and the associated factors is not to be formally established. However, the results provided by the study can be taken into account to improve the health of the mother-child couple in the Kimpese Health Zone.

\section{Conclusion}

The present study focused on the determining factors of delay of PNC 1 in the health zone of Kimpese. The frequency of PNC 1 retardation in this population is high. This frequency is associated with the non-spouse head of household, the existing place of PNC and the lack of coverage of ANC costs. These socio-demographic and economic conditions delaying access to PNC 1 may be revealed in this health zone, finally of a good quality of maternal and antenatal care.

\section{Author Contribution}

LBT designed, collected, interpreted, wrote and corrected the manuscript. AN analyzed the data, read and corrected the article. LNP ande MBJ read and edited the article, MMR supervised, interpreted and edited the article. All authors have read and approved the final version of the article.

\section{Conflict of Interest}

The authors declare that they have no competing interests.

\section{Acknowledgements}

The authors sincerely thank all hospitals and doctors who have agreed to collaborate with us in this context study.

\section{References}

[1] Organisation Mondiale de la Santé (OMS). Recommandations concernant les soins anténatals pour que la grossesse soit une expérience positive, 2016.

[2] Say L, Chou D, Gem mill A et al. Global causes of maternal death: a WHO systematic analysis. Lancet Glob Health 2014 Jun; 2 (6): e323-33.

[3] Organisation des Nations Unies. Transformer notre monde: Le programme de développement durable à l'horizon 2030. Sommet des nations unies consacré à l'adoption du programme de développement pour l'après-2015, Assemblée Générale des Nations Unies, New-York, Septembre 2015.

[4] Haute autorité de santé (HAS), comment mieux informé les femmes enceintes? Recommandation pour les professionnels de santé, Avril 2015.

[5] Redshaw M. and Heikkila K. Delivered with care: a national survey of women'sexperience of maternity care. Oxford: National Perinatal Epidemiology Unit; 2010: 16-32.

[6] Ndidi, E. and Oseremen, I. Reasons given by pregnant women for late initiation of antenatal care in the Niger Delta. Ghana Medical Journal 2010; 44 (2): 47-51. 
[7] Banda I, Michelo C, and Hazemba A. (2012). Factors Associated with late Antenatal Care Attendance in Selected Rural and Urban Communities of the Copperbelt Province of Zambia. Medical Journal of Zambia 2012; 39 (3): 29-36.

[8] Ministère du Plan et Suivi de la Mise en œuvre de la Révolution de la Modernité. Deuxième Enquête Démographique et de Santé (eds-rdc II 2013-2014), 2014; 124-129.

[9] Registre des consultations prénatales, IME-Kimpese 2015.

[10] Bureau Central de la Zone de Santé de Kimpese, 2016.

[11] Chewe, M., Muleya, M. and Maimbolwa, M. (2016). Factors associated with late antenatal care booking among pregnant women in Ndola District, Zambia. AJM 2016, 3: 48-53.

[12] Njiku, F., Wella, H., Sariah, A. and Protas, J. (2017). Prevalence and factors associated with late antenatal care visit among pregnant women in Lushoto, Tanzania. Tanzania Journal of Health Research. 2017; 19 (3): 77-86.

[13] Gebremeskel, F., Dibaba, Y., and Admassu, B. Timing of First Antenatal Care Attendance and Associated Factors among Pregnant Women in Arba Minch Town and Arba Minch District, Gamo Gofa Zone, South Ethiopia. Journal of Environmental and Public Health, 2015: 7.

[14] Okeudo, C., Ezem, U., and Ojiyi, C. Antenatal Care Booking Pattern at a Tertiary Hospital in South-Eastern Nigeria. AFRIMEDIC Journal 2013; 4 (2): 88-96.
[15] Prakash, P., Mihir, R., and Swati P. Antenatal care registration and predicting factors of late registration among pregnant women. Tropical Doctor 2013; 43: 9-12.

[16] Feinstein, F., Mupenda, B., Duvall S., and al. Antenatal and Delivery Services in Kinshasa, Democratic Republic of Congo: Care-seeking and Experiences Reported by Women in a Household-based Survey. Trop Med Int Health 2013; 18 (10): 56-61.

[17] Nsibu, C., Manianga, C., Kapanga, S., and coll. (2016). Determinants of Antenatal Care Attendance among Pregnant Women Living in Endemic Malaria Settings: Experience from the Democratic Republic of Congo. Obstetrics and Gynecology International 2016: 5423413: 7. http://dx.doi.org/10.1155/2016/5423413.

[18] Houri Boukar. Facteurs associés à la non fréquentation des services de Consultations prénatales à l'Extrême Nord cas du District de Santé de Maroua II. The Journal of Medecine and Health Sciences, 2018; 2 (4): 39-45.

[19] Ndiaye P et al. Déterminants socioculturels du retard de la 1re consultation prénatale dans un district sanitaire au Sénégal. Santé Publique 2005; 4 (17): 531-538.

[20] Mafuta EM, Kayembe PK. Déterminants de la fréquentation tardive des services de soins prénatals dans les zones de santé de l'Equateur et du Katanga en République Démocratique du Congo. Ann. Afr. Med. 2011; 4 (4): 23-39. 